\title{
Electrochemical Study of Interaction between Imidazole-Based- Ionic-Liquid and Light Petroleum in Oil/Water Emulsion
}

\author{
E.E. Villalobos-Neri ${ }^{1}$, U. Páramo-García ${ }^{1, *}$, R. Mayen-Mondragon ${ }^{2, *}$, N.V. Gallardo-Rivas ${ }^{1}$ \\ ${ }^{1}$ Tecnológico Nacional de México/I. T. Cd. Madero, Centro de Investigación en Petroquímica, Prol. \\ Bahía de Aldhair y Av. de las Bahías, Parque de la Pequeña y Mediana Industria, 89600, Altamira, \\ Tamaulipas, MÉXICO \\ ${ }^{2}$ Polo Universitario de Tecnología Avanzada, Facultad de Química, Universidad Nacional Autónoma \\ de México, Vía de la Innovación 410, Autopista MTY-Aeropuerto Km. 10, Parque PIIT, 66629, \\ Apodaca, Nuevo León, MÉXICO. \\ *E-mail: uparamo@itcm.edu.mx; rmayen@unam.mx
}

doi: $10.20964 / 2021.06 .59$

Received: 10 February 2021 / Accepted: 15 April 2021 / Published: 30 April 2021

In the present work, the binding capacity of a 1-methyl-3-hexylimidazolium p-toluenesulfonate ionic liquid to Aragon light oil within a 70/30 oil/water emulsion was studied by cyclic voltammetry. The imidazole-based ionic liquid was synthesized by anion interchange reaction. Its chemical structure was confirmed by Fourier-Transform Infrared Spectroscopy and Nuclear Magnetic Resonance. Its Critical Micelle Concentration (CMC) in water was determined by Conductimetry, Ultraviolet-Visible Spectroscopy and Cyclic Voltammetry. The ionic-liquid-to-oil binding-constant and binding-freeenergy were determined from the dependence of the voltammogram anodic-peak-current with the ionic liquid concentration in the emulsion. The diffusion coefficient of the free and bound forms of the oil within the emulsion were determined from the Randles-Sevcik equation. The measurements led to a $\mathrm{CMC}$ value of approximately $152 \mathrm{mg} / \mathrm{L}$ and a binding constant of $0.98 \times 10^{4} \mathrm{M}^{-1}$, corresponding to a binding free energy of $-22.78 \mathrm{KJ} / \mathrm{mol}$. The negative value of the latter confirmed the ionic liquid spontaneously binds to the oil phase. The oil-droplets diffusion coefficient showed a 2.5 -fold increase (up to $4.631 \times 10^{-7} \mathrm{~cm}^{2} / \mathrm{s}$ ) due to incorporation of the ionic liquid molecules. The information gathered can be helpful to design more efficient remediation processes of oil-contaminated water, as well as to improve the design of ionic liquid molecules, and to study their interaction with different oil components.

Keywords: Imidazole, diffusion coefficient, oil/water emulsion, critical micelle concentration, oilcontaminated waters

FULL TEXT 
(C) 2021 The Authors. Published by ESG (www.electrochemsci.org). This article is an open access article distributed under the terms and conditions of the Creative Commons Attribution license (http://creativecommons.org/licenses/by/4.0/). 